\title{
MONITORAMENTO MICROBIOLÓGICO EM SISTEMA INOVADOR SUSTENTÁ VEL DE TRATAMENTO DE ÁGUA DESTINADAÀ HEMODIÁLISE
}

\begin{tabular}{|c|c|}
\hline $\begin{array}{l}\text { Adriano Guimarães Parreira } \\
\text { Universidade do Estado de Minas Gerais } \\
\text { (UEMG e UFSJ) } \\
\text { aguiparreira@ufsj.edu.br }\end{array}$ & $\begin{array}{l}\text { Submetido em: 25/08/2016 } \\
\text { Artigo aceito em: 15/01/2017 }\end{array}$ \\
\hline $\begin{array}{l}\text { Fenando Vieira de Sousa } \\
\text { Universidade do Estado de Minas Gerais (UEMG) } \\
\text { fernandovieira-biologo@hotmail.com }\end{array}$ & \\
\hline $\begin{array}{l}\text { André Prado Rocha } \\
\text { Deltamed } \\
\text { andre@deltamed.ind.br }\end{array}$ & DOI 10.21450/rahis.v13i3.3609 \\
\hline $\begin{array}{l}\text { Thiago Moreira Souza } \\
\text { Hospital São João de Deus } \\
\text { thiago.moreira@hsid.com.br }\end{array}$ & \\
\hline
\end{tabular}

\section{Resumo}

A disponibilidade de água em volumes expressivos e em qualidade incomparável são requisitos básicos para a operação e pleno funcionamento de unidades de hemodiálise. O presente trabalho avaliou a qualidade microbiológica em diferentes pontos de um sistema inovador de tratamento de água destinada a hemodiálise e que prioriza seu reuso, refletindo em importantes ganhos sob o ponto de vista ambiental assim como na racionalização de gastos em um Hospital filantrópico do interior de Minas Gerais. Os resultados confirmam excelência na qualidade microbiológica da água destinada a diálise atendendo aos requisitos e valores máximos permitidos estabelecidos pela legislação específica vigente (Portaria MS 2914/11 e RDC 11/2014).

Palavras-chave: HEMODIÁLISE; SUSTENTABILIDADE, ÁGUA.

\section{MICROBIOLOGICAL MONITORING IN INNOVATIVE AND SUSTAINABLE WATER TREATMENT SYSTEM DESTINED TO HEMODIALYSIS}

\begin{abstract}
The availability of large volumes of water in unparalleled quality are basics requirements for operation full of hemodialysis units. The present study assessed the microbiological quality in different points of an innovative system water treatment to hemodialysis that prioritizes your reuse with reflects in important gains under the environmental viewpoint as well as the rationalization of spending in a Hospital philanthropic of Minas Gerais state. The results
\end{abstract}


confirm excellence in microbial water quality meeting the requirements and maximum allowable values established under current specific Legislation (Law MS 2914/11 and RDC 11/2014).

\title{
VIGILANCIA MICROBIOLÓGICA EM SISTEMA INNOVADOR Y SOSTENIBLES DE TRATAMIENTO DE AGUA DESTINADA A HEMODIÁLISIS
}

\begin{abstract}
Resumen
La disponibilidad de agua en grandes volúmenes y calidad incomparable son requisitos básicos para el pleno funcionamento y operacion de las unidades de hemodiálises. Este estudio tiene como objetivo evaluar la calidad microbiológica en diferentes puntos de un sistema de tratamiento de agua innovador diseñado para la hemodiálisis y priorizar su reutilización reflexionando sobre las ganancias desde el punto de vista ambiental así como la racionalización del gasto de capital de un hospital filantrópico del Minas Gerais . Los resultados confirman la excelencia en la calidad microbiológica del agua de la dialisis in cumplimiento de los requisitos y los valores máximos permitidos establecidos por la legislación específica vigente (Portaria MS 2914/11 y la RDC 11/2014).
\end{abstract}

Palabras clave: HEMODIÁLISIS;SOSTENIBILIDADE; AGUA.

\section{INTRODUÇÃO}

A água é elemento indispensável à manutenção da vida, precioso recurso de natureza finita com distribuição heterogênea e irregular. Variados fatores influenciam na disponibilidade hídrica e contribuem marcadamente para sua redução: aumento da concentração populacional, incremento das atividades produtivas, degradação dos corpos hídricos, efeitos das mudanças climáticas e uso irracional associado a desperdícios, todos associados a sensação de recurso natural infinito (ANA, 2016).

Diante dessa realidade, a busca por racionalizar seu uso por meio de práticas sustentáveis representa um dos principais pilares para a garantia de disponibilidade em volume e qualidade que atendam às necessidades. Porém, o grande aumento por sua demanda, causado pelo consumo crescente, associado à capacidade limitada de resiliência dos sistemas, cria desequilíbrios e cenários de escassez cada vez mais comuns e sem precedentes em diversas regiões do país e do globo. Tendo em vista estes fatos e buscando alcançar real desenvolvimento sustentável, o volume consumido deve ser repensado e práticas de reuso urgentemente adotadas. Tal reuso pode contemplar ao mesmo tempo importantes aspectos que se inter-relacionam: diminuição do consumo com racionalização de gastos e redução na geração de efluentes (METCALF E EDDY, 2003).

No que se refere a sua qualidade, a água utilizada para consumo humano, seja ela proveniente de reuso ou não, requer, primordialmente, o conhecimento de sua condição microbiológica e físico-química com vistas a garantir aos usuários a certeza de que aquele recurso hídrico atende aos pré-requisitos estabelecidos para o fim a que se destina (BRASIL, 2011).Notadamente, no que se refere ao destino no âmbito da saúde, seus parâmetros qualitativos devem ser rigorosamente observados, tendo em vista a particularidade dos usuários envolvidos. Em sistemas de hemodiálise, especialmente, a 
disponibilidade hídrica em volume considerável e qualidade indiscutível é requisito fundamental para um bom funcionamento do sistema e imprescindível para a garantia de sucesso no tratamento dispensado aos portadores de insuficiência renal. Estima-se um consumo médio anual de água tratada por paciente em unidades de hemodiálise em torno de $43.000 \mathrm{~L}$, dos quais aproximadamente $40 \%$ é descartada como efluente, embora, frequentemente, com qualidade superior àquela que entra no sistema (ILHE et al., 1982).

Organismos como bactérias, cianobactérias, vírus, fungos, protozoários e algas, assim como íons e sais de natureza diversa, podem estar presentes na água usada na preparação da solução de diálise, afetando sua qualidade microbiológica e físicoquímica e podendo trazer sérios prejuízos aos pacientes submetidos ao tratamento (CAPELLI et al., 2003; DE FILIPPIS, et al., 2007). Além disso, é importante considerar os efeitos adversos da formação eventual de biofilmes microbianos ao longo das superfícies internas das tubulações, o que pode promover episódios de contaminações recorrentes, aumento da densidade populacional de microrganismos e prejuízos que podem ser irreparáveis aos pacientes em tratamento (MONTANARI et al., 2009).

Com base nestas considerações, o presente trabalho foi desenvolvido com o intuito principal de monitorar a qualidade microbiológica da água destinada à hemodiálise proveniente de um sistema inovador de tratamento. Tal sistema foi desenhado com vistas a privilegiar o reuso de volumes de água, a partir do refluxo de efluentes gerados pós- osmose reversa, configurando-se em um sistema fechado, o que levanta a hipótese de que haveria maior tendência a formação de biofilmes em seu interior propiciando contaminação microbiológica recorrente.

\section{DISPONIBILIDADE HÍDRICA}

A água constitui elemento essencial à vida de todo ser humano; a relevância de suas incontáveis aplicações, seja no abastecimento público, industrial, agropecuário ou na saúde, na preservação da vida aquática, na recreação ou no transporte, demonstra sua vital importância (BECHARA, 1992). O acesso a uma fonte segura e suficiente de água é requisito fundamental para a sobrevivência humana, para o bem estar e para o desenvolvimento sócio-econômico de toda comunidade (GISELLI, 2006).

A abundância de água no planeta causa a falsa sensação de um recurso natural inesgotável, o que pode conduzir a ações inconsequientes e irreversíveis, gerando cada vez mais desperdício e escassez. Cobrindo aproximadamente $3 / 4$ da superfície do planeta, a maior parte da água, $94,7 \%$, é salgada e encontra-se nos oceanos; $1,8 \%$ está congelada nas regiões polares e apenas o restante, $0,8 \%$, é doce e está disponível para o consumo da população mundial, não se conhecendo exatamente a fração correspondente que se encontra contaminada (REBOUÇAS et al., 1999). Em relação às águas superficiais, o Brasil detém 13,7\% do total da água doce do planeta, embora mais de $73 \%$ encontramse disponíveis na bacia Amazônica, habitada por menos que 5\% da população total do país. Por outro lado, apenas $27 \%$ dos recursos hídricos superficiais brasileiros estão disponíveis para as demais regiões, onde residem aproximadamente $95 \%$ da população brasileira (LIMA, 1999). Portanto, mesmo dispondo de recurso hídrico abundante, em virtude de sua má distribuição e má utilização, o Brasil não está livre da ameaça de uma crise de desabastecimento nos próximos anos, sobretudo nos grandes centros urbanos, a exemplo do que vem acontecendo recentemente na cidade de São Paulo e algumas 
cidades do interior de Minas Gerais e outros Estados do Sudeste do país. De forma geral, a redução da disponibilidade hídrica relaciona-se ao rápido e desordenado crescimento populacional e sua concentração em núcleos mal estruturados (CASALI, 2008).

Segundo dados da Organização das Nações Unidas (ONU), em 2011 a população mundial atingiu a cifra dos 7 bilhões de habitantes, ávidos por água abundante e de boa qualidade, suficientemente capaz de garantir sua própria sobrevivência e das próximas gerações. Dados da UNESCO apontavam que, já em 1997, aproximadamente 2,6 bilhões de pessoas não contavam com um serviço de saneamento básico e que uma em cada seis pessoas ainda não usufruía de um sistema de abastecimento de água adequado (SAUNDERS e WARFORD, 1998). Projeções da ONU indicam que, se a tendência continuar até 2050 , mais de $45 \%$ da população mundial estará vivendo em países que não poderão garantir a cota mínima diária de 50 litros de água por habitante (PNUD, 2006). Em virtude disso, em março de 2005, o secretário-geral das Organizações das Nações Unidas (ONU), Kofi Annan, decretou como a Década da Água os anos de 2005 a 2015.

\section{POTABILIDADE DA ÁGUA}

A qualidade necessária para a água destinada ao consumo humano refere-se a sua potabilidade, ou seja, deve ser tratada, limpa e estar livre de qualquer contaminação, seja esta de origem microbiológica, química, física ou radioativa, não devendo, em hipótese alguma, oferecer riscos à saúde humana. Essa potabilidade é alcançada mediante várias formas de tratamento, sendo que a mais tradicional inclui basicamente as etapas de coagulação, floculação, decantação, filtração, desinfecção e a fluoretação. Para que um programa de tratamento, distribuição e armazenamento cumpram com sucesso suas funções é necessário também que o sistema de armazenamento seja eficiente. Para atender a este padrão, a água de abastecimento deve apresentar quantidades limites para diversos parâmetros físico-químicos e microbiológicos que são definidos pelas legislações vigentes, tal qual a portaria $n^{\circ} 2914 / 11$ do Ministério da Saúde (BRASIL, 2011).

A água, acima de tudo, é recurso primordial para o funcionamento e a execução de diversas atividades e processos desenvolvidos no campo da saúde. Especialmente no que se refere ao tratamento de pacientes com insuficiência renal, dependentes de hemodiálise, a disponibilidade de água em quantidade e qualidade suficiente é requisito fundamental para a efetividade do tratamento. Naqueles pacientes o sangue é filtrado artificialmente, por meio de uma máquina e, para isso, é necessária a colocação de um cateter ou a confecção de uma fístula, procedimento executado normalmente nas veias do braço, a fim de se permitir que estas fiquem com maior calibre e assim promover o fluxo sanguíneo adequado para ser filtrado. Em geral, são realizadas três vezes por semana, em sessões com duração média de 3 a 4 horas (ANDREOLI; NADALETO, 2008). A quantidade de água que um paciente utiliza por ano é de aproximadamente 23.000 litros (NYSTRAND, 2008a) e o volume descartado gira em torno de $40 \%$ do volume total que incide no sistema. A preocupação com a enorme demanda pela água em unidades de hemodiálise tem despertado a preocupação de vários pesquisadores no mundo todo, especialmente nos últimos anos dada a escassez de água de boa qualidade no planeta (WARD, 2011). Em Divinópolis MG, somente na unidade de nefrologia de um Hospital Filantrópico cidade são utilizados 400.000 litros de água mensais para 
alimentar o sistema de hemodiálise lá instalado, apesar da economia de 380.000L mensais após a instalação do novo sistema.

\section{SISTEMAS DE HEMODIÁLISE}

Pacientes em hemodiálise não apresentam rins capazes de excretar resíduos de produtos metabólicos do organismo, eles dependem da hemodiálise para a retirada daqueles produtos e normalização dos eletrólitos. O equipamento de diálise mimetiza a função renal bombeando o sangue do paciente através de membranas semipermeáveis "capilares" ou dialisadores - imersos no dialisato, promovendo a filtração dos produtos indesejáveis do sangue (uréia, creatinina, ácidos orgânicos, medicamentos, etc.) substituídos pelos íons presentes no dialisato (cálcio, sódio e potássio) (LEME; SILVA, 2003).O deslizador ou capilar, também conhecido como rim artificial, é um filtro constituído por dois compartimentos (em um deles passa o sangue e em outro o dialisato). Esses compartimentos são separados por uma membrana semipermeável construída a partir de finos tubos plásticos, semipermeáveis e com inúmeros poros de tamanho microscópico. O dialisador apresenta tamanho e volumes de enchimentos variados, definidos para cada paciente e dependentes da prescrição médica (OLIVEIRA JUNIOR, 2008). A água tratada deve seguir por tubulações aparentes em PVC ou similar, com conexões em locais estratégicos dentro do circuito, a fim de facilitar o controle de qualidade da mesma (LEME; SILVA, 2003).

Os sistemas de tratamento de água para diálise são compostos de filtros mecânicos, abrandadores (equipamento cuja principal aplicação é a remoção dos íons de cálcio e magnésio responsáveis pela dureza contidiana água), filtros de carvão, deionizadores, osmose reversa e tanques para armazenamento da água (MONTANARI et al., 2009).

\section{QUALIDADE DA ÁGUA DESTINADA A HEMODIÁLISE}

A qualidade da água que circula nos sistemas de hemodiálise é um dos itens mais preocupantes e rigorosos, já que sua situação físico-química e microbiológica afeta diretamente a condição clínica do paciente. Água com quantidade mínima de contaminantes, de origem orgânica ou inorgânica, poderá trazer prejuízos muitas vezes irreparáveis aos pacientes submetidos ao tratamento, além de gerar insegurança aos profissionais de saúde diretamente envolvidos. Com o aumento do número de pacientes em tratamento dialítico e de sua sobrevida, acumularam-se evidências que permitem correlacionar contaminantes presentes na água a efeitos adversos ao longo do tratamento (SILVA et al., 1996). Desde que começaram os primeiros tratamentos com hemodiálise em pacientes com insuficiência renal crônica avanços foram alcançados no que se refere as exigências da qualidade da água empregada. No início, não havia rigor no controle da qualidade da água utilizada, no entanto face a vários incidentes causados por água de má qualidade melhorias foram sendo exigidas e implementadas.

Organismos como bactérias, vírus, fungos, protozoários e algas, podem estar presentes na água usada na preparação da solução de diálise. Isso pode ocorrer quando o sistema de tratamento de água passa por processos de desinfecção ineficientes (CAPELLI et al., 2003; DE FILIPPIS, et al. 2007). 
Devido à presença de contaminantes associado ao aumento no número de clínicas e de pacientes em tratamento por hemodiálise, os controles se fizeram necessários e os limites de aceitabilidade da água, destinada ao preparo da solução de diálise, tornaram-se cada vez mais rigorosos. O reconhecimento do risco potencial de contaminantes químicos e microbiológicos levou à criação, em várias partes do mundo, de órgãos e comissões que estabeleceram critérios para a composição adequada da solução de diálise. Hospitalizações relacionadas às infecções em pacientes de hemodiálise estão associadas com significativa morbidade, internação em unidades de terapia intensiva e prolongada hospitalização. Em função do fato do sangue e dialisato serem separados apenas por uma membrana semipermeável, a vigilância da qualidade microbiológica da água de diálise e do dialisado é extremamente importante. Os fluídos não precisam ser estéreis, mas o número máximo de micro-organismos deve ser controlado (SILVA et al., 1996).

\section{CONTAMINAÇÃO MICROBIOLÓGICA DOS SISTEMAS E RISCOS INERENTES}

Especial atenção deve ser dada aos biofilmes microbianos que se formam ao longo dos sistemas e que representam nichos responsáveis por contaminações recorrentes, a partir do desprendimento de células jovens que deixam de integrar aquele nicho. Em sistemas de fluxo contínuo tal possibilidade representa fator de grande relevância e preocupação. A contaminação microbiológica da água raramente tem origem na fase de fluido, ou seja, na água, mas sim sobre as superfícies do sistema. Dessa forma, a água em seu fluxo contínuo transporta material microbiológico das tubulações para as máquinas de diálise. O material inclui células microbianas, endotoxinas e metabólitos microbianos formados durante o crescimento no interior do equipamento (NYSTRAND, 2008a).

Smeets et al. (2003) concluíram, em estudo realizado em duas clínicas cuja água era submetida a tratamentos diferenciados, que contrastando com o sistema padrão, o uso de um sistema com água altamente purificada levou a uma significativa redução na formação de biofilmes, crescimento bacteriano, e menores níveis de endotoxinas em uma parte vulnerável do sistema de tratamento. A contaminação do dialisato por bactérias e a potencial transferência das mesmas para o sangue tem sido reportada como um fator de predisposição em complicações clínicas durante tratamento crônico por hemodiálise, embora este particular seja eventualmente negligenciado (BRUNET; BERLAND, 2000).

Resultados de estudos multicentros indicam que a qualidade microbiana do fluido de diálise ainda representa um sério problema pouco discutido, particularmente pela dificuldade de se levantar evidências de uma possível relação entre contaminação do fluido com morbidade a longo prazo (PONTORIERO; POZZONI; LOCATELLI, 2003).

No Brasil, em meados de fevereiro de 1996, uma epidemia de origem obscura assolou uma clínica de hemodiálise conveniada com o Sistema Único de Saúde (SUS), o Instituto de Doenças Renais (IDR), de Caruaru, Pernambuco. Em março de 1996, a Secretaria de Saúde daquele estado foi informada do aparecimento de sintomas como cefaléia, tontura, distúrbios visuais e astenia em cerca de trinta pacientes do serviço. Inicialmente, os efeitos adversos foram atribuídos a uma possível hipercloração da água 
usada pela clínica, abastecida por meio de caminhões pipa. Além dos sintomas informados, os pacientes apresentavam também desorientação mental, convulsões, náuseas e vômitos. Passarem então a exibir um quadro clínico compatível com hepatite tóxica: icterícia, ascite, hepatomegalia dolorosa, flapping e alterações significativas nas transaminases e bilirrubinas. Além da intoxicação pelo cloro, outras hipóteses foram levantadas: intoxicação por metais pesados ou agrotóxicos, infecção por bactérias, vírus e outros. Levantou-se, por fim, a hipótese de que a sintomatologia dos pacientes era consequiência de sua exposição, durante o procedimento de hemodiálise, a toxinas de cianobactérias contidas na água. Havia semelhança do quadro clínico e da histopatologia hepática dos pacientes com o que se observava em animais de laboratório após exposição a essas toxinas. Foram divulgados resultados positivos da detecção de microcistina nos filtros de hemodiálise do IDR. No mesmo período, técnicos do Center for Disease Control (CDC), de Atlanta, Estados Unidos, iniciavam in loco a investigação epidemiológica. Em meados de abril, o professor Wayne Carmichael (Wright State University, Ohio) informou que a pesquisa de microcistina no sangue e no tecido hepático dos pacientes fora positiva, estando ausente no sangue do grupo de controle. No período de fevereiro de 1996 a setembro de 1997, a taxa de mortalidade foi de 40,5\% (51 óbitos por hepatite pós-exposição a toxinas de cianobactérias numa população de 126 inscritos no programa de hemodiálise). Os grupos de maior risco de morte foram os homens na faixa etária acima de sessenta anos.

Em Ponta Grossa, Paraná, setenta e duas amostras de água e de dialisato foram coletadas em unidades de hemodiálise de novembro de 2003 a abril de 2004 . O teste de coliformes totais e fecais produziu resultados negativos para todas as amostras, enquanto a contagem total de bactérias heterotróficas apresentou três amostras de água e duas de dialisato com níveis superiores aos permitidos pelos padrões nacionais, 200 e $2000 \mathrm{UFC} / \mathrm{mL}$, respectivamente.

Pacientes com insuficiência renal não só estão expostos aos maiores volumes de água em sua vida que a população geral, mas a barreira entre o sangue e o líquido de diálise é geralmente uma membrana semipermeável não seletiva, proporcionando uma rota direta para quaisquer contaminantes na corrente sanguínea. De modo especial, pacientes em hemodiálise estão propensos a infecções oportunistas devido, sobretudo à exposição a antibióticos, acesso vascular freqüente e alteração da imunidade celular (KATHRESAL et al., 2008).

Ouyang et al. (2008) reportaram um caso de bacteremia relacionadas a cateter em paciente submetido a hemodiálise por Paenibacillus thiaminolyticus, um bacilo Gram-positivo aeróbico. Bactérias intactas não podem atravessar a membrana do dialisador, porém produtos bacterianos tais como endotoxinas, peptídeos e exotoxinas, são potentes indutores de citocinas e estimuladores da resposta de fase aguda são capazes de estimular células mononucleares e contribuir para a inflamação crônica, associada à terapia por hemodiálise a longo prazo. Essa transferência está relacionada ao tipo de membrana do dialisador e ao modo de diálise (HOENICH e RONCO, 2007).

Com base nestas considerações e no reconhecimento de que a tecnologia de osmose reversa, estabelecida como a melhor alternativa de purificação empregada em unidades de hemodiálise, demanda consumo e desperdício de água extremamente significativos, o presente trabalho buscou avaliar a condição microbiológica da água circulante em um sistema fechado e inovador destinado ao tratamento da água consumida na unidade de hemodiálise do setor de Nefrologia de um Hospital 
filantrópico em Divinópolis MG. Importante ressaltar que o sistema em funcionamento propicia uma economia mensal aproximada de $380.000 \mathrm{~L}$ de água e o efluente destinado ao reuso apresenta valores de condutividade aproximadamente $10 \mathrm{X}$ inferiores àqueles das amostras de água que nele entram diretamente, refletindo assim qualidade superior sob o ponto de vista físico-químico, quando comparada a água disponibilizada pela agência de saneamento e abastecimento da cidade. Especificamente, o presente trabalho objetiva pesquisar a eventual presença de coliformes totais ou termotolerantes em alguns pontos do sistema, isolar e quantificar bactérias heterotróficas totais eventualmente presentes; identificar bactérias mais frequentemente encontradas e levantar dados físico-químicos das amostras coletadas, comparando-se os resultados obtidos com a legislação vigente, Portaria MS 2914/11 (BRASIL, 2011) e Resolução RDC 11/2014 (BRASIL, 2014).

\section{METODOLOGIA}

\section{COLETA DAS AMOSTRAS E DESCRIÇÃO DO SISTEMA}

Os experimentos foram conduzidos a partir da coleta de volumes de água em pontos de amostragens e monitoramento de um sistema inovador de tratamento de água destinado à hemodiálise, dotado de refluxo pós-osmose reversa priorizando assim o reuso, em funcionamento na unidade de hemodiálise do Setor de nefrologia de um Hospital filantrópico de Divinópolis MG.

Os pontos de amostragens selecionados foram: 1-ponto de entrada principal (E), 2- ponto de reuso $(\mathrm{R}), 3$-ponto anterior a resina catiônica (AR),4-ponto de coleta pósresina catiônica (PRC),5-ponto pós-resina aniônica (P Res Ani), 6-pós osmose (PO) e7pós reservatório (Pres), conforme ilustração na Figura 1. Foram realizadas coletas mensais entre setembro e dezembro de 2015 e janeiro de 2016, obedecendo-se criteriosamente a aspectos fundamentais de assepsia além de transporte imediato sobre refrigeração do material colhido e encaminhado diretamente ao Laboratório de Microbiologia da UEMG-Unidade Divinópolis MG para o início imediato dos procedimentos laboratoriais de avaliação. As coletas foram iniciadas após autorização dos Comitês de Ética em Pesquisa com Seres Humanos da UEMG-Unidade Divinópolis e do Comitê de Ética do Hospital filantrópico, com registros na Plataforma BrasilConep (Comitê Nacional de Ética em Pesquisa com Seres Humanos) sob N.47888015.8.0000.5115 e N.47888015.8.3001.5130, respectivamente. 


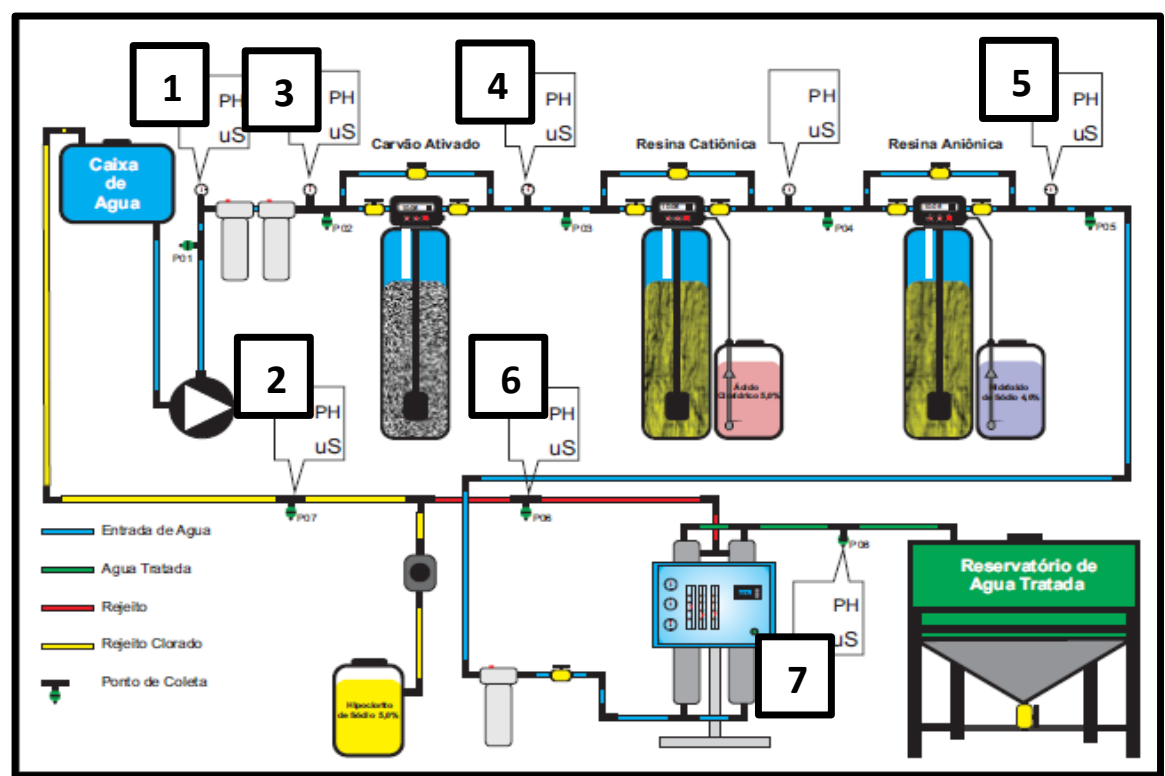

Fig. 1 Ilustração dos componentes do sistema de tratamento de água destinada a hemodiálise com os respectivos pontos de coleta destacados em negrito (detalhes no texto).

\section{CONTAGENS DE BACTÉRIAS HETEROTRÓFICAS}

As contagens de bactérias heterotróficas foram realizadas mediante a execução do método de plaqueamento em profundidade (Pour Plate) (APHA; AWWA; WPCF, 2005). A partir de alíquotas de $1 \mathrm{~mL}$, coletadas assepticamente em cada um dos pontos de amostragem, foram realizadas diluições seriadas em tubos de cultura contendo $9 \mathrm{~mL}$ de salina $0,85 \%(\mathrm{p} / \mathrm{v})$, utilizando-se de capela de fluxo laminar. Foram transferidos 1 $\mathrm{mL}$ a cada tubo totalizando diluições de $10^{-1}$ a $10^{-6}$, seguindo-se de plaqueamentos em placas de Petri contendo meio Ágar nutriente ${ }^{\circledR}$ de composição gL $^{-1}$ : peptona 5,0; extrato de levedura 1,5; extrato de carne 1,5; cloreto de sódio 5,0; Àgar 15,0.Para as contagens foram selecionadas as diluições contendo de 30 a $300 \mathrm{UFC} \mathrm{mL}^{-1}$ sendo que as mesmas foram feitas em triplicata.

A avaliação das características macroscópicas das colônias que cresceram nas placas indicou aquelas a serem repicadas e cultivadas em placas isoladas a fim de se executar posteriormente os testes de identificação bacteriana. A avaliação bioquímica baseou-se nos testes IMVic ( Indol, Vermelho de metila, Voges-Proskauer, Citrato) além dos testes de hidrólise de amido e fermentação de açúcares, seguindo-se orientações contidas em TORTORA et al. (2005). Vale ressaltar que, adicionalmente, o meio de cultivo Àgar-BHI foi também testado, a fim de se averiguar eventuais diferenças de crescimento microbiano comparativamente ao meio Àgar-nutriente, sendo selecionado este último dado o maior espectro de crescimento bacteriano em placas para amostras de mesma origem. Colônias com características diversas e mais comumente encontradas foram selecionadas para identificação a nível de espécie por espectrometria de massas. 


\section{AVALIAÇÃO DA PRESENÇA DE COLIFORMES TOTAIS E TERMOTOLERANTES}

Para a avaliação da presença de bactérias do grupo coliforme foi empregada a técnica do substrato cromogênico (Koneman, 2001), utilizando-se para tal Kit Colitest ${ }^{\circledR}$ (LPK Diagnósticos). Um total de $100 \mathrm{~mL}$ de água coletada em cada ponto de amostragem foi adicionado a frascos estéreis contendo $20 \mathrm{~g}$ do substrato cromogênico. Em seguida, os frascos foram incubados em estufa a $37^{\circ} \mathrm{C}$ por $48 \mathrm{~h}$. Transcorrido aquele intervalo, seguiu-se a avaliação da eventual mudança de cor (púrpua para amarela) da solução, indicativa da presença de coliformes totais na amostra. As amostras positivas foram submetidas à análise da presença de coliformes termotolerantes quando da formação de anel azul sob luz UV (ultravioleta) e teste de Kovacs. Este procedimento foi aplicado às amostras coletadas no ponto de entrada principal e no ponto de reuso.

\section{AVALIAÇÃo DE PARÂMETROS FÍSICO-QUÍMICOS}

A avaliação da presença de íons na água, correspondendo à eventual contaminação química, foi efetivada com base nos valores de condutividade apresentados nos registradores utilizados rotineiramente para aquele tipo de monitoramento. Igualmente, os valores encontrados foram comparados com os valores de referência da Legislação vigente e a freqüência de amostragens seguiu aquela da avaliação da presença de microrganismos. Esporadicamente, foram avaliados também os valores de $\mathrm{pH}$ das amostras coletadas nos referidos pontos e algumas características organolépticas da água também observadas. 


\section{RESULTADOS E DISCUSSÃO}

A Tabela 1, apresentada abaixo, sintetiza os resultados obtidos a partir das análises das amostras coletadas, perfazendo um total de 7 (sete) pontos de amostragem do sistema em um total de 5 coletas ao longo de 5 meses de análises.

\begin{tabular}{|c|c|c|c|c|c|c|}
\hline \multicolumn{4}{|c|}{ COLETAS REALIZADAS NO HOSPITAL SÃO JOÃO DE DEUS } & \multicolumn{3}{|c|}{ RESULTADO DAS ANÁLISES } \\
\hline data da coleta & ponto de coleta & identificação da amostra & PH & $\begin{array}{c}\text { coliformes } \\
\text { totais }\end{array}$ & $\begin{array}{c}\text { coliformes } \\
\text { termotolerantes }\end{array}$ & $\begin{array}{c}\text { bactérias } \\
\text { heterotróficas }\end{array}$ \\
\hline \multirow{7}{*}{$15 / 09 / 15$} & Entrada (copasa) & $E$ & não realizado & negativo & negativo & negativo \\
\hline & Reuso & $R$ & não realizado & negativo & não realizado & 600 UFC/ML \\
\hline & Anterior resína catiônica & AR & não realizado & não realizado & não realizado & não realizado \\
\hline & Pós resina catiônica & PRC & não realizado & não realizado & não realizado & não realizado \\
\hline & Pós resina aniônica & PRes Ani & não realizado & não realizado & não realizado & negativo \\
\hline & Pós osmose & PO & não realizado & não realizado & não realizado & negativo \\
\hline & Pós reservatório & P.Res & não realizado & não realizado & não realizado & negativo \\
\hline \multirow{7}{*}{$12 / 10 / 15$} & Entrada (copasa) & $E$ & 6,99 & negativo & negativo & negativo \\
\hline & Reuso & $R$ & 8,27 & negativo & não realizado & 8900 UFC / ML \\
\hline & Anterior resína catiônica & AR & não realizado & não realizado & não realizado & não realizado \\
\hline & Pós resina catiônica & PRC & não realizado & não realizado & não realizado & não realizado \\
\hline & Pós resina aniônica & PRes Ani & 8,15 & não realizado & não realizado & negativo \\
\hline & Pós osmose & PO & 7,1 & não realizado & não realizado & negativo \\
\hline & Pós reservatório & P.Res & 8,1 & não realizado & não realizado & negativo \\
\hline \multirow{7}{*}{$24 / 11 / 15$} & Entrada (copasa) & $E$ & 7,02 & negativo & negativo & negativo \\
\hline & Reuso & $R$ & 8,6 & nggativo & não realizado & 1.000 UFC/ML \\
\hline & Anterior resína catiônica & AR & 7,6 & não realizado & não realizado & negativo \\
\hline & Pós resina catiônica & PRC & 2,78 & não realizado & não realizado & negativo \\
\hline & Pós resina aniônica & PRes Ani & 6,75 & não realizado & não realizado & negativo \\
\hline & Pós osmose & PO & 4,3 & não realizado & não realizado & negativo \\
\hline & Pós reservatório & P.Res & 7,47 & não realizado & não realizado & negativo \\
\hline \multirow{7}{*}{$15 / 12 / 15$} & Entrada (copasa) & $E$ & não realizado & negativo & negativo & negativo \\
\hline & Reuso & $R$ & não realizado & negativo & não realizado & 63.300 UFC / ML \\
\hline & Anterior resína catiônica & $A R$ & não realizado & não realizado & não realizado & não realizado \\
\hline & Pós resina catiônica & PRC & não realizado & não realizado & não realizado & não realizado \\
\hline & Pós resina aniônica & PRes Ani & não realizado & não realizado & não realizado & 850 UFC / ML \\
\hline & Pós osmose & PO & não realizado & não realizado & não realizado & negativo \\
\hline & Pós reservatório & P.Res & não realizado & não realizado & não realizado & negativo \\
\hline \multirow{7}{*}{$06 / 01 / 15$} & Entrada (copasa) & $E$ & não realizado & negativo & negativo & negativo \\
\hline & Reuso & $R$ & não realizado & não realizado & não realizado & 300 UFC / ML \\
\hline & Anterior resína catiônica & $A R$ & não realizado & não realizado & não realizado & não realizado \\
\hline & Pós resina catiônica & PRC & não realizado & não realizado & não realizado & não realizado \\
\hline & Pós resina aniônica & PRes Ani & não realizado & não realizado & não realizado & negativo \\
\hline & Pós osmose & $\mathrm{PO}$ & não realizado & não realizado & não realizado & negativo \\
\hline & Pós reservatório & P.Res & não realizado & não realizado & não realizado & negativo \\
\hline
\end{tabular}


A partir dos resultados listados na Tabela 1 é possível perceber, notadamente, que apenas as amostras provenientes do ponto de coleta $\mathrm{R}$ (reuso) apresentaram valores discrepantes no que se refere a contagens de bactérias heterotróficas totais, variando ao longo dos períodos de coleta de $600 \mathrm{UFC} \mathrm{mL}^{-1}$ a $63300 \mathrm{UFC} \mathrm{mL}^{-1}$. No entanto, ao se considerar os pontos de coleta posteriores ao ponto $\mathrm{R}$ e o ponto imediatamente posterior ao reservatório ( $\mathrm{P}$ res), a partir do qual a água é direcionada às máquinas de diálise, observa-se que não é encontrada sequer uma colônia de bactérias heterotróficas crescendo em meio de cultivo Ágar-nutriente, demonstrando assim que as etapas de tratamento da água posteriores ao ponto $\mathrm{R}$ efetivamente são capazes de eliminar a presença daqueles microrganismos naquele fluido. Além do mais, etapa adicional de tratamento da água com lâmpada germicida ultravioleta é integrada ao sistema na posição pós-reservatório, o que garante ainda maior segurança sob o ponto de vista microbiológico.

No tocante aos dados quantitativos de bactérias heterotróficas totais, a Resolução RDC 11/2014 (BRASIL, 2014) deixa claro que para a água disponibilizada ao uso final em sistemas de hemodiálise deve-se observar um VMP (valor máximo permitido) de $100 \mathrm{UFC} \mathrm{mL}^{-1}$ estando, portanto, o sistema em análise dentro dos padrões estabelecidos, na medida em que constata-se ausência completa de heterotróficos ao final do tratamento, ou seja, ponto $\mathrm{P}$ res (pós-reservatório). Além disso, para a coleta do dia 12 de dezembro também observou-se crescimento de heterotróficas totais no ponto PRC que, da mesma forma, não foi detectado nos pontos subseqüentes e nem mesmo nas coletas que se seguiram ao longo dos meses seguintes.

A Figura 2 apresentada abaixo ilustra duas das placas de petri inoculadas com amostras coletadas no ponto $\mathrm{R}$ (reuso), indicando crescimento de colônias de bactérias heterotróficas com características macroscópicas diversas (coloração, forma, tamanho, brilho e consistência) que permitiram com que fossem isoladas e repicadas em novas placas a fim de se executar os procedimentos de coloração de Gram e caracterização bioquímica, baseada nos testes IMViC, hidrólise de amido e fermentação de açúcares. Foram repicadas as colônias de bactérias que apresentavam características distintas em todos os momentos em que se verificava crescimento bacteriano nas placas. As colônias isoladas indicaram cepas bacterianas de espécies de bastonetes Gram-negativos e cujos resultados de caracterização bioquímica apontaram para os gêneros Aeromonas sp e Sphingomonas sp. Importante ressaltar que estes foram os gêneros mais comumente encontrados dentre todos os observados ao longo das coletas e experimentos de isolamento, observando-se ainda a presença de Lactobacillus murinus e Pandoraea norimbergensis, identificadas por espectrometria de massas com análise de proteínas ribossomais, não citadas, contudo, na literatura como microrganismos comuns em sistemas de hemodiálise. Registros na literatura corroboram com nossos resultados confirmando presença de bactérias dos gêneros Pseudomonas sp (LECLERC e MOREAU, 2002; GOMILA,2005) Sphingomonas sp (GOMILA, 2005) e Aeromonas sp (LECLERC e MOREAU, 2002) comumente encontradas em amostras de água de sistemas de tratamento destinadas a hemodiálise. Especial atenção deve ser dada a Pseudomonas aeruginosa, tendo em vista sua performance na formação de biofilmes ao 
longo das tubulações do sistema com possibilidade de contaminação recorrente (REIS, 2010).

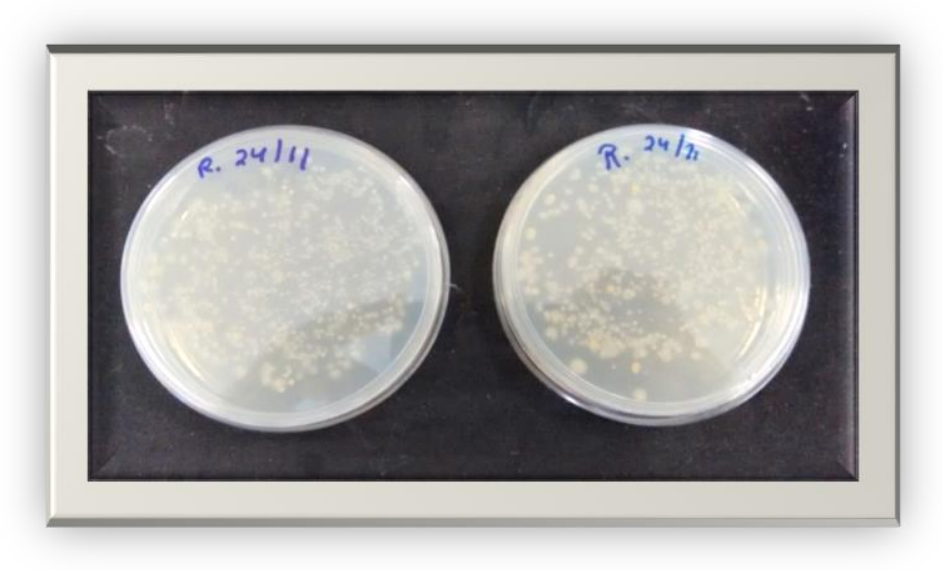

Fig. 2Placas de petri com colônias de bactérias heterotróficas provenientes da inoculação de amostras de água coletadas no ponto de coleta reuso (R) em meio Àgar-nutriente.

Em relação às bactérias do grupo coliforme, totais ou termotolerantes, as mesmas apresentaram-se ausentes na totalidade de amostras coletadas em todos os pontos selecionados para sua verificação (Tabela 1), especificamente na entrada do sistema e ponto de reuso, atendendo desta forma as determinações estabelecidas pela Resolução RDC 11/2014 da ANVISA e Portaria 2914/11 do Ministério da Saúde, que definem como água própria para o uso em sistemas de hemodiálise e destinada ao consumo para seres humanos, respectivamente, aquelas amostras ausentes de coliformes totais em um volume total de $100 \mathrm{~mL}$, de acordo com a procedência das mesmas. A Figura 3 abaixo ilustra a apresentação de uma amostra coletada no ponto de entrada (E), após período de incubação e em frasco específico para tal, demonstrando a manutenção da coloração púrpura indicativa da ausência de coliformes totais, conforme descrição técnica e orientações do fornecedor.

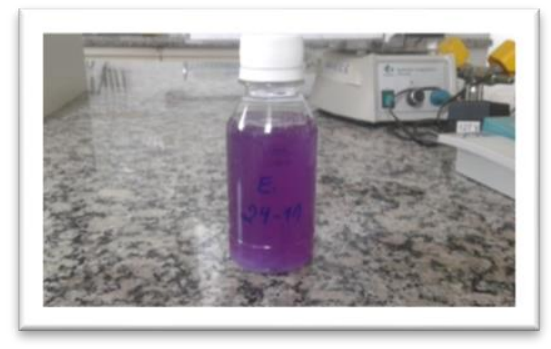

Fig. 3 Frasco com solução em púrpura indicando ausência de contaminação com coliformes totais seguindo técnica do substrato cromogênico. 
No que se refere aos parâmetros físico-químicos não se observou nenhuma distorção para quaisquer das situações avaliadas, comparativamente a legislação específica (RDC 11/2014), ou seja, os valores de $\mathrm{pH}$ estiveram dentro da faixa de 6,0 a 9,5; os valores de condutividade estavam bem abaixo do limite de 10,0 microSiemens/cm, VMP definido pela legislação, permanecendo em média entre 0,30,6 microSiemens/cm o que indica, neste particular, água com qualidade ainda superior àquela que entra no sistema, fornecida pela agência pública de abastecimento e que apresenta condutividade média de 4,0 microSiemens $/ \mathrm{cm}$. Anteriormente a instalação do sistema aqui apresentado há relatos de que a condutividade média nos pontos de monitoramento mantinha-se em torno de 3,0 microSiemens $/ \mathrm{cm}$.

Associadas a essas análises, características organolépticas também foram observadas no momento da coleta das amostras, sendo constatada água límpida, de aparência incolor, sem turvação, sem cheiro e ausentes de partículas em suspensão, atendendo igualmente aos quesitos constantes nas determinações da Resolução RDC 11/2014. Água de boa qualidade, tanto sob o aspecto microbiológico quanto físicoquímico, reflete diretamente na saúde do paciente com insuficiência renal submetido a hemodiálise, a exemplo de estudos indicando que a baixa mortalidade de pacientes japoneses submetidos a hemodiálise tem relação direta com o controle rigoroso da qualidade da água destinada a hemodiálise executado no Japão (HASEGAWA et al., 2015).

Importante ressaltar que a nova configuração do sistema de tratamento de água destinada a hemodiálise e, em funcionamento, foi patenteada junto ao INPI (Instituto Nacional de Propriedade Industrial) e foi contemplada com o primeiro lugar no Prêmio Mineiro de Inovação, categoria processo, concedido pela Câmara Ìtalo-Brasileira de Comércio, Indústria e Artesanato de Minas Gerais em sua edição de 2014, refletindo a originalidade e importância da proposta apresentada.

\section{CONSIDERAÇÕES FINAIS}

Os resultados obtidos apontam para excelência na qualidade da água destinada a hemodiálise, considerando-se aspectos microbiológicos e físico-químicos, ao longo de sistema inovador de tratamento adotado em uma unidade de hemodiálise de um hospital filantrópico de Divinópolis MG. Foi comprovada ainda que a hipótese levantada de que haveria maior tendência de formação de biofilmes e contaminação microbiológica significativa do fluido circulante não se confirmou, sobretudo para este momento. Importante ressaltar também os inegáveis ganhos em termos ambientais e financeiros, quando se considera uma redução mensal de $380.000 \mathrm{~L}$ no consumo de água naquela unidade.

Sugere-se, contudo, monitoramento permanente do sistema no tocante a condição microbiológica do fluido circulante e atenção especial ao ponto $\mathrm{R}$ (reuso), tendo em vista se tratar de um novo sistema com circulação contínua com retroalimentação dos fluidos circulantes. 


\section{REFERÊNCIAS BIBLIOGRÁFICAS}

ANA - Agência Nacional das Águas - Disponível em <www.ana.gov.br>, acesso em Julho de 2016.

ANDREOLI, M. C. C.; NADALETTO, M. A. Diálise. Disponível em:< ttp://www.sbn.org.br/leigos/index.php?dialise\&menu=8> Acesso em 11/10/2014.

BECHARA, E.J. H. O Homem e o Meio Ambiente. Química Nova, v.15 (2), p. 117, 1992.

BRASIL. Ministério da Saúde. Portaria n. 2914, 12 de dezembro de 2011. Diário Oficial da Republica Federativa do Brasil. Brasília: Ministério da Saúde, 2011.

BRASIL. MS. RDC - Resolução da Diretoria Colegiada $\mathbf{n}^{\mathbf{0}}$ 11, de 13 de março de 2014. Estabelece o Regulamento Técnico para o funcionamento dos Serviços de Diálise Brasília-DF. Disponível em: <http://www.anvisa.gov.br/legis/>. Acesso em: 05/01/2016.

BRUNET, P.; BERLAND, Y. Water quality and complications of haemodialysis. Nephrology Dialysis Transplantation, Oxford, v.15, p.578 - 580, 2000.

CAPELLI, G.; SERENI, L.; SCIALOJA, M.G.; MORSELLI, M.; PERRONE, S.; CIUFFREDA, A.; BELleSIA. M.; INGUAGgiATO, P.; AlBERTAZZI, A.; TETTA, C. Effects of biofilm formation on haemodialysis monitor disinfection. Nephrology Dialysis Transplantation, Oxford, v. 18, p. 2105-2111, 2003.

DE FILIPPIS, P.; SPINACI, A.; SPITALERI, G.; DAMIANI, F.; PANÀ, A. Testing for Pseudomonas aeruginosa: na additional parameter assessing microbiological quality of dialysis water. Igiene e Sanità Pubblica, Roma, v. 61, n. 5, p. 467-474, 2005. 
CASALI, C. A.Qualidade da Água para Consumo Humano Ofertada em Escolas e Comunidades Rurais da Região Central do Rio Grande do Sul. Dissertação (Mestrado) Curso de Pós-Graduação em Ciência do Solo, UFSM, Santa Maria (RS), 173p., 2008.

GISELLI GISIAINE. Avaliação da Qualidade das Águas Destinadas ao Abastecimento Público na Região de Campinas: Ocorrência e Determinação dos Interferentes Endócrinos (IE) e Produtos Farmaêuticos e de Higiene Pessoal (PFHP). Tese (Doutorado)- Curso de Doutorado em Química - UNICAMP, Campinas SP, 190p. 2006.

GOMILA, M.; GASCÓ, J.; BUSQUETS, A.; GIL, J.; BERNABEU, R.; BUADES, J.M.;LALUCAT, J. Identification of culturable bacteria present in haemodialysis water andfluid. FEMS Microbiology Ecology, Oxford, v. 52, p. 101-114, 2005.

HASEGAWA, T. Dialysis Fluid Endotoxin Level and Mortality in Maintenance Hemodialysis: A Nationwide CohortStudy. Am. J Kidney Dis. v 65(6), p. 899-904. 2015.

HOENICH, N.; RONCO, C. Haemodialysis Fluid: Composition and Clinical Importance. Blood Purification, Basilea, v. 25, p. 62-68, 2007.

IHLE B, BUCHANAN M, STESENS B, MARSHAL A, KINCAID-SMITH P. Aluminium associated bone disease: clinic-pathologic correlations. Am J Kidney Dis. v.11, p. 255-263, 1982.

KATHRESAL, A.; BIUNDO, J.; BLAIS, C.M.; MORSE, S.; REISIN, E. A rare case of Candida arthritis in a hemodialysis patient. The American Journal of the Medical Sciences, Philadelphia, v. 336, n. 5, p. 437-440, 2008.

KONEMAM, E. W. et al. Diagnóstico microbiológico: Textos e Atlas. $5^{\text {a }}$ edição, Ed.Medsi. Rio de Janeiro, 2001

LECLERC, H.; MOREAU, A. Microbiological safety of natural mineral water.FEMS Microbiology Reviews, v. 26, p. 207-222, 2002. 
LEME, I.L.; SILVA, V.G. Recomendações para a garantia da qualidade da água para uso em unidades de hemodiálise. Associação Brasileira de Centros de Diálise e Transplantes, 2003.

LIMA, J. E. F. W; FERREIRA, R. S. A; CHRISTOFIDIS, D. O uso da irrigação no Brasil. In: Estado das águas no Brasil: Perspectivas de gestão e informação de recursos hídricos. SIH/ANEEL/MME; SRH/MMA. p. 73-82, 1999.

METCALF \& EDDY. Wastewater engineering : treatment and reuse. 4. ed. Boston: McGraw-Hill, 1819 p. 2003.

MONTANARI, L.B.; SARTORI, F.G.; CARDOSO, M. J.O.; VARO, S.D.; PIRES, R. H.; LEITE, C. Q. F.; PRINCE, K.; MARTINS, C.H.G. Contaminação microbiológica no sistema de distribuição de água de um centro de hemodiálise. Revista do Instituto de Medicina Tropical de São Paulo, São Paulo, v. 51, n. 1, p. 37-43, 2009.

NYSTRAND, R. Microbiology of Water and Fluids for Hemodialysis, review article. Journal Chinese Medical Association, Taipei, v. 71, n. 5, p.223-229, 2008.

OLIVEIRA JUNIOR, V.T. Água filtrada na hemodiálise. Meio Filtrante, ano VII, n. 32, mai.-jun. 2008. Disponível em: < http://www.meiofiltrante.com.br/materias_ver.asp?action=detalhe $\& i d=382 \&$ revista=n3 2>. Acesso em: 21/10/2014.

PNUD - Programa das Nações Unidas para o Desenvolvimento. Relatório do Desenvolvimento Humano. A água para lá da escassez: poder, pobreza e a crise mundial da água. New York (USA). 1101p., 2006.

PONTORIERO, G.; POZZONI, S.A.; LOCATELLI, F. The quality of dialysis water. Nephrology Dialysis Transplantation, Oxford, v. 18, suppl. 7, p. 21-25, 2003.

REBOUÇAS, A. C., BRAGA, B., TUNDISI. J.G. Águas Doces no Brasil: capital ecológico, uso e conservação. Revista Escrituras -1 ed. São Paulo (SP). 150p., 1999. 
REIS, B. A. B.Produção de biofilme por bastonetes Gram negativos não fermentadores isolados de água de hemodiálise.Trabalho de conclusão de curso Bacharelado - Ciências Biológicas -Instituto de Biociências de Botucatu, Universidade Estadual Paulista, 2010.

SAUNDERS, R. J E WARFORD, J. J. Abastecimento de Água em Pequenas Comunidades: aspectos econômicos e políticos nos países em desenvolvimento. ABES/ CODEVASF/ BNH. Rio de Janeiro RJ: 252p., 1983.

SILVA, A.M.M.; MARTINS, C.T.B.; FERRABOLI, V.J.; ROMÃO JUNIOR, J.E. Revisão/ Atualização em diálise: Água para hemodiálise. Jornal Brasileiro de Nefrologia, São Paulo, v. 18, n. 2, p. 180-188, 1996.

SMEETS, E.; KOOMAN, J.; VAN DER SANDE, F.; STOBBERING, E.; FREDERIK, P.; CLAESSENS, P.; GRAVE, W.; SCHOT, A.; LEUNISSEN, K. Prevention of biofilm formation in dialysis water treatment systems. Kidney International, New York, v. 63, p. 1574-1576, 2003.

TORTORA, G.J., FUNKE, B.R., CASE, L.C. Microbiologia. 8. ed. Porto Alegre: Artmed, 894p., 2005.

WARD, R. A.Avoiding Toxicity From Water-Borne Contaminantsin Hemodialysis: New Challenges in an Era of IncreasedDemand for Water. Advances in Chronic Kidney Disease, V.18, p. 207-213, 2011. 